\title{
NOVOS AMBIENTES PARA O ENSINO DE FILOSOFIA
}

\author{
Alan Marx Francisco \\ Antonio Sanches Valera Neto
}

\section{RESUMO}

O ensino de filosofia encontra inúmeras dificuldades, tanto pela sua estrutura mais abstrata quanto pela sua linguagem própria; nosso projeto fundamenta-se na filosofia de Gilles Deleuze e Félix Guattari investigando assim um meio alternativo às metodologias de ensinos atuais. As mídias eletrônicas foram escolhidas como campo para desenvolvimento do nosso trabalho, em específico através do jogo Filosofighters no qual oito filósofos de diferentes períodos históricos duelam entre si, a proposta é trabalhar através dos golpes de cada filósofo seus conceitos. O trabalho contou com a participação dos alunos do ensino médio do Colégio Estadual Barão do Rio Branco que apresentaram significantes resultados de fixação e interesse no conteúdo. Considerando que a filosofia é a arte de formar, de inventar e fabricar conceitos; o jogo possibilita condições favoráveis para que entre amigos em uma situação diversificada do contexto de sala e de certa rivalidade os alunos formulem conceitos, ou seja, faça aquilo que é próprio do fazer filosófico. Palavras-chave: Jogos, Ensino de Filosofia e conceito

\section{INTRODUÇÃO}

Gilles Deleuze (1925-1995) e Félix Guattari (1930-1992) não são especialmente filósofos da educação e em geral seus textos não estão diretamente voltados a esse importante tema, porém suas contribuições inovadoras no campo da filosofia propriamente dito nos dão margem para uma possível interpretação de seu conteúdo, à luz da fillosofia da educação, devido a engenhosidade em buscar algo próprio da filosofia, que ao mesmo tempo abraçasse a multiplicidade de pensamentos que garantisse ao individuo o protagonismo. Deleuze e Guattari dão de presente para a filosofia da educação um campo fértil de possibilidades e experiências para buscar o fazer e o pensar filosófico no âmbito escolar.

O presente trabalho é uma tentativa de buscar essas experiências, com base nos pensamentos desses filósofos, um ambiente, dentro das novas possibilidades de metodologias de ensino, propicio a esse pensar e fazer filosófico. O trabalho busca uma interpretação da fillosofia de Deleuze e Guattari através dos estudos desenvolvidos pelo professor de filosofia da educação Sílvio Gallo(1963- ). A discussão parte das ideias apresentadas na última obra de Deleuze e Guattari, intitulada como "O que é a Filosofia?", se estendendo a outras obras e conceitos mais específicos do pensamento dos autores, em paralelo com a contribuição de Sílvio Gallo, e seguida pelo relato da experiência ocorrida no Colégio Estadual Barão do Rio Branco, com a aplicação de uma nova metodologia de ensino possível ao pensar e fazer filosóficos. 


\section{SEMINÁRIO DE PESQUISA EM CIÊNCIAS HUMANAS - SEPECH \\ Humanidades, Estado e desafios didático-científicos \\ Londrina, 27 a 29 de julho de 2016}

\section{O QUE É A FILOSOFIA?}

Em seu último livro publicado, Deleuze em companhia com Guattari se dispõe a responder essa questão, buscando aquilo que consideram, já tardiamente, uma definição do que vieram a fazer a vida toda. A resposta vem já no primeiro capitulo do livro "A filosofia é a arte de formar, de inventar de fabricar conceitos" (Deleuze, G.; Guattari, F. O que é a Filosofia. p.13.)

O filósofo é o amigo do conceito, ele é conceito em potência. Quer dizer que a filosofia não é uma simples arte de formar, de inventar ou de fabricar conceitos, pois os conceitos não são necessariamente formas, achados ou produtos. A filosofia, mais rigorosamente, é a disciplina que consiste em criar conceitos [...] Criar conceitos sempre novos, é o objeto da filosofia. É porque o conceito deve ser criado que ele remete ao filósofo como àquele que o tem em potência, ou que tem sua potência e sua competência [...] Que valeria um filósofo do qual se pudesse dizer: ele não criou um conceito, ele não criou seus conceitos? (Deleuze, G.; Guattari, F. O que é a Filosofia. p.13.)

Distante da filosofia de Deleuze e Guattari essa resposta, mesmo que aparentemente simples, não vem vazia de conteúdo e merece certa disposição por parte do leitor para entender melhor o que se pretende dizer com isso. Para tanto, a resposta não termina assim, pois ambos os filósofos nos apresentam que esses conceitos não estão sozinhos, e para que possam existir é necessário coexistir um personagem conceitual e traçar um plano de imanência. Só então se pode definir o que é a filosofia. É necessário ter em mente que a definição de filosofia depende da coexistência entre personagem conceitual, plano de imanência e criação de conceitos. Dessa forma ela se apresenta como resposta voltada, não para o campo da educação, mas sim para o campo próprio da filosofia, e de fato podemos pensar desse modo. Entretanto, como aponta Sílvio Gallo:

Parece-me que não apenas àqueles que se puseram a pensar e a escrever sobre educação têm algo a dizer aos educadores; ousadamente, diria que talvez aqueles que não explicitamente se debruçaram sobre a problemática educacional tenham mais a dizer aos educadores do que podemos imaginar. (Gallo, S. Deleuze e a Educação. P.3)

As inovações apresentadas por Deleuze e Guattari quando estes se preocupam em definir a filosofia nos possibilitam a imersão dessas inovações a fim de propor no campo da educação caminhos possíveis para se pensar uma nova forma de atuação.

A filosofia para ambos os filósofos se difere de uma espécie de contemplação filosófica que se apresenta passiva frente ao mundo, tal como a proposta platônica para a filosofia, aquela a qual contempla as ideias e o abstrato. Não é também a diferenciação feita por Aristóteles de uma vida ativa como sendo a vida politica e a vida filosófica como contemplação, se divergindo assim, da filosofia incipiente dos gregos. Deleuze e Guattari estão propondo uma filosofia que cria conceitos e esse criar é necessariamente agir no mundo e atuar nele, ao ponto de, através da criação de 


\section{SEMINÁRIO DE PESQUISA EM CIÊNCIAS HUMANAS - SEPECH \\ Humanidades, Estado e desafios didático-científicos \\ Londrina, 27 a 29 de julho de 2016}

conceitos, ser permitido ao filosofo criar um mundo a sua maneira, necessariamente, atuando e agindo nele.

A filosofia não é contemplação muito menos reflexão ou comunicação, uma vez que essas três características pertencem também a outras áreas do conhecimento, como na matemática, que faz uso da reflexão dos problemas matemáticos e também da comunicação. A preocupação de Deleuze e Guattari está em buscar algo próprio e único da filosofia. E essa singularidade é a criação de conceitos. Assim, de inicio, nos atemos em compreender o que é o conceito.

\subsection{Conceito}

Deleuze e Guattari buscam a definição de conceito, ou melhor, conceituar o próprio conceito. Neste passo, apresentam algumas características que em muito divergem da ideia de conceito que temos corriqueiramente como sendo a definição de algo ou ideia sobre alguma coisa. O conceito para os autores apresenta as seguintes particularidades:

$1^{\circ}$ o conceito é exposto através de uma linguagem que possui sua significação bem peculiar, obedecendo aos requisitos do pensamento de ambos os autores. Onde o movimento do conceito é exaltado como pensar filosoficamente, que por sua vez, possui uma incontrolável força diante ao fluxo da realidade. Configurandose assim, a imagética do devir como uma máxima do conceito em si, e, da linguagem deleuzeana.

$2^{\circ}$ o conceito é assinado, próprio de cada filosofo, que para tanto atribui à linguagem uma semântica própria para tal tarefa;

$3^{\circ}$ o conceito é múltiplo, isto é, um conceito não é sozinho, ele próprio se refere a outros conceitos que se referem a outros conceitos, e assim por diante, daí o fato dele ser múltiplo não se esvazia dele uma aparente totalidade, melhor dizendo ele é um todo fragmentado;

$4^{\circ}$ o conceito é criado a partir de problemas, ele é provocado, não vindo a nascer do nada, ele é criado para solucionar esse problema;

$5^{\circ}$ o conceito é histórico; ele perpassa um contexto histórico independente do contexto que está inserido, porém, ele não é linear, pois ele age como um ziguezague, indo e voltando no devir histórico;

$6^{\circ}$ o conceito é relativo e absoluto ao mesmo tempo, ele é relativo quanto ao seu contexto e quanto à necessidade de haver nele outros conceitos, porém, é absoluto quanto ao problema que se propõe a responder;

Os conceitos nada mais são do que heterogêneses, sendo ordenados por zonas de vizinhança, que permitem uma visão de mundo possível; assim explica Sílvio Gallo:

O conceito não é uma "entidade metafísica", ou um "operador lógico", ou uma "representação mental". O conceito é um dispositivo, uma ferramenta, algo que é inventado, criado, produzido, a partir das condições dadas e que opera no âmbito mesmo destas condições (Ibdem. p.21). 


\section{SEMINÁRIO DE PESQUISA EM CIÊNCIAS HUMANAS - SEPECH \\ Humanidades, Estado e desafios didático-científicos \\ Londrina, 27 a 29 de julho de 2016}

O conceito possibilita o pensar e o pensar possibilita o conceito, resultando em uma visão de mundo que não foge dos acontecimentos que propiciam o conceito. Porém para melhor entender os conceitos passamos a entender melhor o plano de imanência e qual sua relação com o conceito.

\subsection{Plano de Imanência}

O plano de imanência é o trabalho filosófico, é campo de atuação dos conceitos, é o plano de instauração do conceito, onde este nasce; e pode ser entendido como sendo o local onde o conceito atua, relacionando-se com o problema, o contexto histórico e suas outras características. Ele é necessariamente a condição pela qual propicia a existência da filosofia, podendo ser entendido, portanto, como pré-fílosófico; porém, eles não estão separados, pois quando se cria um conceito, imediatamente se tem com ele um plano de imanência novo ou já existente, e da relação comum a ambos se extrai a filosofia. Assim melhor explica Sílvio Gallo:

Dizer que o plano de imanência é pré-filosófico não significa, porém, que ele seja anterior à filosofia, mas que ele é uma condição interna e necessária para que a filosofia exista. Logo, plano de imanência e conceito surgem juntos, um implicando necessariamente o outro: "A filosofia é, ao mesmo tempo, criação de conceito e instauração do plano. O conceito é o começo da filosofia, mas o plano é sua instauração." O início da filosofia é a criação de conceitos (filogeneticamente - história da filosofia, e ontogeneticamente aparecimento de cada filósofo singular), mas no próprio momento em que se criam os conceitos há a instauração de um plano de imanência que, a rigor, é a instauração da própria filosofia, pois se assim não fosse os conceitos criados ficariam perdidos no vazio. (Ibdem. p. 22)

O plano de imanência pode ser criado pelos filósofos ou estes podem atuar dentro de planos já existentes, como é o exemplo de neokantianos ou neoplatônicos. É possível admitir múltiplos planos, pois podem existir diferentes trabalhos filosóficos. Isso se dá em razão de que no mundo há a existência de um caos, sendo esse caos definido como a multiplicidade de possibilidades.

O plano de imanência toma do caos determinações, com as quais faz seus movimentos infinitos ou seus traços diagramáticos. Pode-se, devese então supor uma multiplicidade de planos, já que nenhum abraçaria todo o caos sem nele recair, e que todos retêm apenas movimentos que se deixam dobrar juntos [...] Cada plano opera uma seleção do que cabe de direito ao pensamento, mas é essa seleção que varia de um para outro. Cada plano de imanência é Uno-Todo: não é parcial, como um conjunto científico, nem fragmentário, como os conceitos, mas distributivo, é um 'cada um'. O plano de imanência é folhado. (Deleuze, G.; Guattari, F. O que é a filosofia? p. 68) 


\subsection{Personagem conceitual}

O personagem conceitual de Deleuze e Guattari nada mais é do que o operador do plano de imanência. É o sujeito pelo qual se dispõe o filósofo a expor e estruturar seu plano de imanência, o que pode aparecer de forma clara em alguns filósofos como Platão, que tem como personagem conceitual Sócrates, ou em Nietzsche, com seus personagens como Zaratustra ou o Anti-Cristo. Assim explica Sílvio Gallo:

Esses personagens conceituais "operam os movimentos que descrevem o plano de imanência do autor, e intervêm na própria criação de seus conceitos". É o personagem conceitual, o heterônimo, portanto, que acaba sendo o sujeito da filosofia, é ele quem manifesta "os territórios, desterritorializaçães e reterritorializaçães absolutas do pensamento" ( Gallo, S. p. 25).

É importante entender que a filosofia para Deleuze e Guattari é a junção desses três aspectos: inventar o personagem conceitual, traçar um plano de imanência e criar conceitos. É relevante ressaltar que dessa filosofia nasce a multiplicidade do pensamento e uma gama de conhecimentos que não estão no mundo para ser postas como verdades absolutas, mas estão para atuarem dentro do seu campo de interesse e possibilidade.

\section{EXPERIÊNCIA E O NOVO AMBIENTE PARA O ENSINO DA FILOSOFIA}

É importe darmos atenção que, para Deleuze, e todo esse "movimento", ou esse fazer filosófico, que está atrelado á criação de conceito dentro de um plano de imanência por um personagem conceitual, demanda tempo, e não é um exercício fácil, como se de um dia para o outro alguém decida ser filósofo e comece a criar conceitos. Isso pode demandar quase toda uma vida, entretanto nesse caso, cabe a nós enquanto Professores a tentativa amenizar essa demanda de tempo, sendo possível entender que uma das principais funções do Professor é propiciar ao aluno o acesso a essa multiplicidade do pensar, aproximando do aluno os conceitos e, por consequência, os planos de imanência e seus personagem conceituais. Pois como notamos na filosofia de Deleuze e Guattari é da multiplicidade do pensar que se pode extrair um novo pensar, uma singularidade.

Nesse sentido a apreensão de conceitos não deve se ater ao foco de compreendê-los no sentido que esvaziar dele a possibilidade de discussão, ou em uma prerrogativa de universalização do mesmo, o que é, de certo modo, absurdo pela própria característica da filosofia que possibilita a multiplicidade de pensamentos e não tem a pretensão de ser uma verdade absoluta. $\mathrm{O}$ modo pelo qual se busca o conhecimento, no pensamento de Deleuze e Guattari, não pode ser visto também como uma massiva apresentação de conceitos, como se fosse papel do Professor empurrar ao aluno a maior quantidade possível de conceitos. $O$ conhecimento está na percepção dessa multiplicidade e não na apreensão de todos os conceitos possíveis.

A experiência proposta no trabalho feito com o jogo Filosofighters está em buscar no âmbito escolar, dentro de novas ferramentas metodológicas um ambiente que 


\section{SEMINÁRIO DE PESQUISA EM CIÊNCIAS HUMANAS - SEPECH \\ Humanidades, Estado e desafios didático-científicos \\ Londrina, 27 a 29 de julho de 2016}

possibilite compreender a multiplicidade de pensamento, ao mesmo tempo em que facilita buscar um interesse do aluno pela disciplina. Buscamos, então, nas mídias digitais, o jogo Filosofighters, no qual nove filósofos de diferentes períodos históricos duelam entre si, onde seus ataques são referentes a um conceito exposto por seu pensamento. Após explicarmos seus contextos históricos e os problemas dos quais cada filosofo se propõe a trabalhar, foi sugerido aos alunos, divididos em nove grupos, cada qual com seu próprio filosofo, que através do jogo duelassem entre si. O meio alternativo da mídia digital do jogo possibilitou que notássemos nos alunos um apreço ou aproximação dos personagens e de seus conceitos, por ora, tidos como golpes. Dada a rivalidade do duelo, foi também exigido aos alunos que respondessem algumas questões formuladas como requisitos para classificação nos duelos.

\section{CONCLUSÃO}

Foi possível notar que, com o desenvolvimento da experiência junto com o novo ambiente das mídias digitais, na proposta do jogo criou-se entre os alunos certo interesse pelos filósofos e seus golpes (conceitos), o que acaba facilitando a introdução do conteúdo, ou melhor, a própria apresentação do filosofo e seus conceitos. Como foram nove os filósofos apresentados no jogo, tornou-se evidente a possibilidade de se trabalhar a multiplicidade do pensamento em seu todo e a singularidade de cada filosofo como. Por exemplo: Platão com seus golpes do homem ideal e da caverna, Karl Marx com os operários unidos e a foice e o martelo, entre outros; são diferentes conceitos, diferentes planos de imanência e diferentes personagens conceituais que exemplificam cada modo de pensar e ver o mundo.

No que diz respeito à criação de conceito pelo aluno, é possível interpretar que o próprio Deleuze afasta essa possibilidade, pois para se chegar a uma singularidade, não é algo fácil e demanda tempo. Como foi explicado acima, no entanto, para a educação pensada no âmbito escolar não estamos exigindo uma originalidade (criação de conceitos) tanto quanto a filosofia necessita para ser reconhecida. Considerando que Deleuze e Guattari não tem em seu escopo uma filosofia da educação. Mas como Professores, temos que assumir essa postura autentica que esta presente na obra $O$ que é a filosofia? E ensinar o pensar filosoficamente, a relevância do conceito para tal. Despertar o aluno a existência multiplicidade, sua descoberta do seu próprio plano de imanência, nesse sentido, em buscar aproximação dos alunos desse múltiplo pensar. Que atribuir o uso da mídia eletrônica na forma do jogo é uma ferramenta possível a se buscar a compreensão da filosofia como gênese do conceito.

\section{BIBLIOGRAFIA}

Deleuze, G./ Guattari, F. - O que é a filosofia? 2º ed.; Editora 34 Ltda, São Paulo, 2007.

Sílvio Gallo - Deleuze e a educação. extraído de: http://www.ufjf.br/grupar/files/2014/09/deleuze_e a educacao parte um.pdf 


\section{SEMINÁRIO DE PESQUISA EM CIÊNCIAS HUMANAS - SEPECH \\ Humanidades, Estado e desafios didático-científicos}

Londrina, 27 a 29 de julho de 2016

Japiassú, H./ Marcondes, D. Dicionário Básico de Filosofia,3 edição; Jorge Zahar Editor, Rio de Janeiro, 2008.

Morente, Manuel García. Lições preliminares de Filosofia. $8^{\circ}$ ed.; Mestre Jou, São Paulo, 1980. 